\title{
Effects of noni on cellular viability and osteogenic differentiation of gingiva-derived stem cells demonstrated by RNA sequencing and quantitative PCR
}

\author{
YOUNG-MIN SONG ${ }^{1 *}$, HYUN-JIN LEE $^{1 *}$, SAE-KYUNG MIN ${ }^{1 *}$, YOON-HEE PARK $^{2}$, \\ JAE-KWEN $\mathrm{OH}^{3}$, JI-YOUN $\mathrm{KIM}^{4}$ and JUN-BEOM PARK ${ }^{1}$
}

${ }^{1}$ Department of Periodontics, College of Medicine, The Catholic University of Korea, Seoul 06591; ${ }^{2}$ Ebiogen, Seoul 04785;

${ }^{3}$ Merden Dental Hospital, Bucheon-si, Gyeonggi $14544 ;{ }^{4}$ Division of Oral and Maxillofacial Surgery,

Department of Dentistry, College of Medicine, St. Vincent's Hospital,

The Catholic University of Korea, Seoul 06591, Republic of Korea

Received June 17, 2021; Accepted October 13, 2021

DOI: $10.3892 / \mathrm{etm} .2021 .10954$

\begin{abstract}
Noni fruit (Morinda citrifolia) has been widely used in traditional medicine across tropical and subtropical regions, and is now being paid more attention in Western medicine. The present study aimed to investigate the effects of noni extract on the change in the cellular morphology, maintenance of cellular viability and enhancement of osteogenic differentiation of stem cells. Stem cells obtained from gingiva were cultured where noni extracts existed at concentrations ranging from 10-200 ng/ml. Evaluations of cell morphology and cellular viability were performed. Alkaline phosphatase activity assays were performed to assess the osteogenic differentiation. Alizarin Red S staining was performed to evaluate the calcium deposits in the culture, with the addition of noni extract. Global gene expression was analyzed via next-generation mRNA sequencing. Gene ontology and pathway analyses were performed to determine the associated mechanisms. Validation procedures were performed via quantitative (q) PCR analysis. The addition of noni at concentrations ranging from 10-200 ng/ml did not produce significant morphological changes. There were significantly higher values of cellular viability, with the highest value at $100 \mathrm{ng} / \mathrm{ml}$ compared with
\end{abstract}

Correspondence to: Dr Jun-Beom Park, Department of Periodontics, College of Medicine, The Catholic University of Korea, 222 Banpo-daero, Seocho-gu, Seoul 06591, Republic of Korea

E-mail: jbassoon@catholic.ac.kr

Dr Ji-Youn Kim, Division of Oral and Maxillofacial Surgery, Department of Dentistry, College of Medicine, St. Vincent's Hospital, The Catholic University of Korea, 222 Banpo-daero, Seocho-gu, Seoul 06591, Republic of Korea

E-mail:kimjy@catholic.ac.kr

*Contributed equally

Key words: cell differentiation, cell survival, herbal medicine, medical plants, Morinda citrifolia, osteogenesis, stem cells the control $(\mathrm{P}<0.05)$. Furthermore, significantly higher values of alkaline phosphatase activity was noted in the 10 and $100 \mathrm{ng} / \mathrm{ml}$ groups compared with the $0 \mathrm{ng} / \mathrm{ml}$ group on day 7 $(\mathrm{P}<0.05)$. Alizarin Red S staining revealed calcium deposits in each group. In addition, the highest value for Alizarin Red S staining was observed at $100 \mathrm{ng} / \mathrm{ml}$ compared with the unloaded control $(\mathrm{P}<0.05)$. qPCR analysis demonstrated that the mRNA expression levels of RUNX2, BSP, OCN and COL1A1 increased following treatment with noni. Taken together, the results of the present study suggest that noni extract has enhancing effects on gingiva-derived mesenchymal stem cells, by enhancing cellular viability and osteogenic differentiation.

\section{Introduction}

Noni fruit (Morinda citrifolia) has been widely used in traditional medicine across tropical and subtropical regions and is now being paid more attention in Western medicine (1). Noni has been used for the treatment of cuts, bruises, bone fractures and other wounds to promote connective tissue regenerations, and to decrease infection and inflammation traditionally $(2,3)$. Currently, noni has also been applied and studied for the treatment of flu, pain, diabetes, hypertension and cancer (4). In addition, noni has been applied in the dental field (5-8). Aqueous extract of noni fruit has an inhibitory effect on Streptococcus mutans and Streptococcus mitis, which are associated with dental caries (5). Furthermore, noni juice has been used in root canal irrigation due to its antimicrobial effects against Enterococcus faecalis and Candida albicans (7). In a human intervention study, rinsing and swallowing of noni juice improved periodontitis as a result of the anti-inflammatory properties of noni juice (6). Advanced periodontitis results in damaged alveolar bone (8). For the treatment of periodontitis, regeneration of alveolar bony defects is important, as well as inflammation control (9). The mineralization properties of noni also have been studied. In a previous pilot clinical study, bone turnover increased in a group of postmenopausal women who had consumed noni 
juice (10). However, the effect of noni on gingival-derived stem cells remains unknown.

Human mesenchymal stem cells possess the ability to differentiate into multiple tissues, including the bone (11). Among the mesenchymal stem cells, gingiva-derived stem cells have comparable multilineage differentiation potential, including osteogenic potential and may be favorable harvesting stem cells source $(12,13)$. Therefore, gingiva-derived stem cells are good sources of studying the effect of noni on mineralization for the treatment of periodontal defect. In a previous study, noni was applied for stem cell spheroids (14). It was shown that noni extract enhanced osteogenic differentiation of stem cell spheroids. Considering the promising findings in previous studies $(11,14)$. The present study aimed to investigate the effects of noni extract on maintaining morphology, improving cellular viability and strengthening osteogenic differentiation of stem cells.

\section{Materials and methods}

Preparation of noni extract. Fig. 1 depicts a general view of the design of the present study. Noni (Morinda citrifolia) was obtained from Ngaraard (Ngiwal, Palau) from a plant $>15$ years. The noni fruit was ripened at room temperature $\left(20-28^{\circ} \mathrm{C}\right)$ at a humidity of $60-85 \%$ for $11-12$ weeks. The noni liquid was freeze dried using a lyophilizer (Ilshin Lab Co., Ltd.) (14).

Culturing of gingiva-derived stem cells and evaluation of the characteristics of stem cell morphology. Gingival stem cells were acquired from a healthy patient receiving periodontal treatment, as previously described (13). The present study was approved by the Institutional Review Board of The Catholic University of Korea (approval nos. KC19SESI0234 and KC20SISE0696; approval date, 07 May 2019) and written informed consent was provided prior to the study start. The stem cells were plated at $2 \times 10^{3}$ cells/well into 96-well plates and incubated in osteogenic media comprising $\alpha$-MEM (Gibco; Thermo Fisher Scientific, Inc.), dexamethasone, glycerophosphate disodium salt hydrate, ascorbic acid 2-phosphate and L-glutamine in the presence of noni, with final concentrations of $0,10,100$ and $200 \mathrm{ng} / \mathrm{ml}$ (G1, G2, G3 and G4), respectively. The morphological characteristics of the cells were evaluated using an inverted light microscope at x40 magnification on day 7 .

Determining cellular viability. Qualitative analysis of cellular viability was performed on days 1 and 7 via the commercially available two-color assay (Live/Dead Kit assay, Molecular Probes; Thermo Fisher Scientific, Inc.), which determines both the plasma membrane integrity and esterase activity (15). Quantitative analysis of viable cells was performed via the Cell Counting Kit-8 assay (Dojindo Laboratories, Inc.), where absorbance was measured at $450 \mathrm{~nm}$, using a spectrophotometer (BioTek Instruments, Inc.). Cells were incubated at room temperature for $1 \mathrm{~h}$.

Evaluation of Alizarin Red S of alkaline phosphatase activity assays and Alizarin Red S staining under osteogenic media. Alkaline phosphatase activity was determined on days 7 and 14, after detaching cells using trypsin and Alkaline Phosphatase
Activity Colorimetric Assay kit (cat. no. K412-500; BioVision Inc.), according to the manufacturer's instructions at $405 \mathrm{~nm}$ (16). Cells were washed, fixed and stained with 2\% Alizarin Red S solution (cat. no. 0223; ScienCell Research Laboratories, Inc.) for $30 \mathrm{~min}$ at room temperature, and quantification of the bound dyes was performed by applying 10\% cetylpyridinium chloride (cat. no. C0732; Sigma-Aldrich; Merck KGaA) for $15 \mathrm{~min}$ at $560 \mathrm{~nm}$ (17).

RNA isolation, library preparation, sequencing and data analysis. Total RNA was extracted from the gingiva-derived stem cells using TRIzol ${ }^{\circledR}$ reagent (Invitrogen; Thermo Fisher Scientific, Inc.). RNA quality was assessed using Agilent 2100 bioanalyzer (Agilent Technologies, Inc.) and RNA quantification was performed using a spectrophotometer (ND-2000; Thermo Fisher Scientific, Inc.). Libraries were prepared from total RNA using the NEBNext Ultra II Directional RNA-Seq kit (New England BioLabs, Inc.). The isolated mRNAs were reverse transcribed into cDNA, according to the manufacturer's instructions (New England BioLabs, Inc.). Quantification was performed using the library quantification kit (18) and library concentration was measured using Tape Station HS D1000 Screen Tape (Agilent Technologies, Inc.). The library loading volume and loading concentration were $150 \mu 1$ and $300 \mathrm{pM}$, respectively. Sequencing was performed using Illumina Novaseq 6000 (Illumina, Inc.). The NovaSeq 6000 S4 Reagent kit v1.5 (300 cycles; Illumina, Inc.) was used as the sequencing reagent kit. Running format was set at PE100bP. Quality control of raw sequencing data was performed and low quality reads $(<Q 20)$ were removed (19). Estimation of gene expression levels and normalization of the values were performed $(19,20)$. Pathway analysis was performed on differentially expressed genes using the Kyoto Encyclopedia of Genes and Genomes mapping tool (21). Data mining and graphic visualization were performed using ExDEGA (Ebiogen, Inc.) (22).

Quantification of RUNX2, BSP, OCN and COL1A1 mRNA expression levels via quantitative (q)PCR. Total RNA was extracted from the gingiva-derived stem cells using a commercially available kit (Thermo Fisher Scientific, Inc.), according to the manufacturer's instructions (17). The quality of RNA was assessed using a bioanalyzer, and RNA quantity was evaluated using a spectrophotometer (ND-2000; Thermo Fisher Scientific, Inc.). RNA was reverse transcribed into cDNA using reverse transcriptase (SuperScript II; Invitrogen; Thermo Fisher Scientific, Inc.).

mRNA expression levels were detected via qPCR analysis on days 3 and 7. GenBank was used to design the sense and antisense primers for PCR. The following primer sequences were used: RUNX2 (accession no. NM_001015051.3; forward, 5'-CAGTTCCCAAGCATTTCATCC-3' and reverse, 5'-AGG TGGCTGGATAGTGCATT-3'), BSP (accession no. NM_004967.4; forward, 5'-CCTCTCCAAATGGTGGGTTT-3' and reverse, 5'-ATTCAACGGTGGTGGTTTTC-3'), OCN (accession no. NM_199173.6; forward, 5'-GGTGCAGAGTC CAGCAAAGG-3' and reverse, 5'-GCGCCTGGGTCTCTTCA CTA-3'), COL1A1 (accession no. NM_000088.4; forward, 5'-TACCCCACTCAGCCCAGTGT-3' and reverse, 5'-CCGAAC CAGACATGCCTCTT- 3 '); and $\beta$-actin (accession. no. NM 001101; forward, 5'-AATGCTTCTAGGCGGACTATGA-3' and 


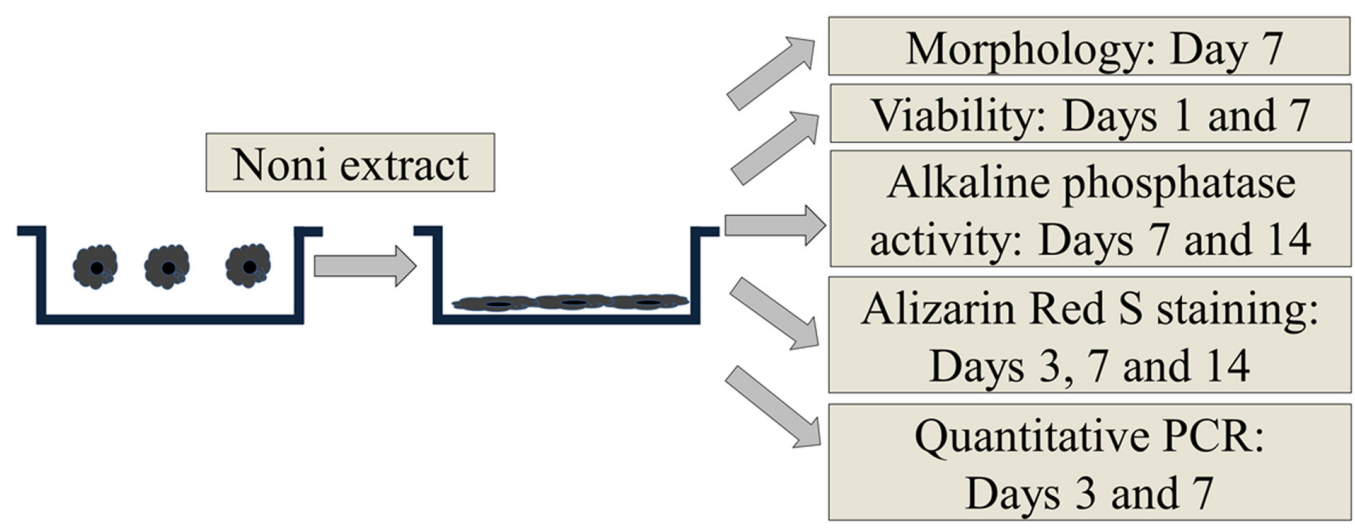

Figure 1. Design of the present study.
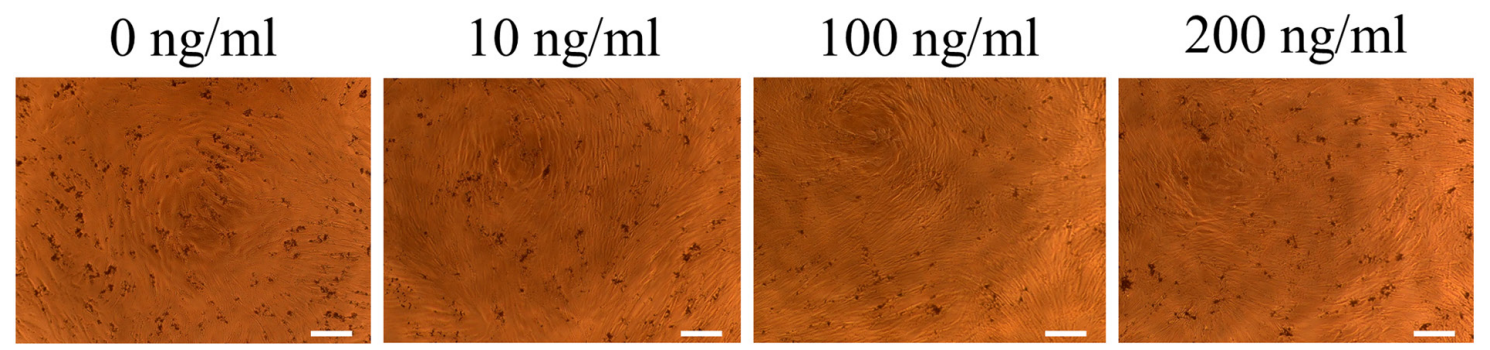

Figure 2. Cell morphology on day 7. Cells were treated with different concentrations of noni (10, 100 and $200 \mathrm{ng} / \mathrm{ml})$, but failed to produce any significant morphological changes compared with untreated control cells. Scale bar, $200 \mu \mathrm{m}$.

reverse, 5'-TTTCTGCGCAAGTTAGGTTTT-3'). DNA synthesis and PCR amplification were performed using a qPCR detection system (StepOnePlus Real-Time PCR System, Applied Biosystems; Thermo Fisher Scientific, Inc.). qPCR was performed using 2X Power SYBR-Green Master Mix (Applied Biosystems; Thermo Fisher Scientific, Inc.). The following thermocycling conditions were used: $95^{\circ} \mathrm{C}$ for $15 \mathrm{~min}$, followed by 40 cycles of $95^{\circ} \mathrm{C}$ for $15 \mathrm{sec}$ and $\mathrm{Tm}$ at $59^{\circ} \mathrm{C}$ for $30 \mathrm{sec}$. Relative expression levels were calculated using the $2^{-\Delta \Delta \mathrm{Cq}}$ method (23) and normalized to the internal reference gene $\beta$-actin.

Statistical analysis. Statistical analysis was performed using SPSS 12 software (SPSS, Inc.). All experiments were performed in triplicate and data are presented as the mean \pm standard deviation. The Shapiro-Wilk test was used to assess normality. One-way ANOVA followed by Tukey's post hoc test was used to compare differences between multiple groups. $\mathrm{P}<0.05$ was considered to indicate a statistically significant difference.

\section{Results}

Evaluation of stem cell morphology and determination of cellular viability. The structures of cells grown in osteogenic media on day 7 are presented in Fig. 2. Treatment with noni at 10,100 and $200 \mathrm{ng} / \mathrm{ml}$ did not yield noticeable morphological changes. The qualitative viability of stem cells was analyzed via a Live/Dead kit assay on days 1 and 7 (Fig. 3A and B). In all cases, most stem cells exhibited a fibroblast-like shape with intense green fluorescence, suggesting the presence of live cells on day 1 (Fig. 3A). Longer incubation of cells on day 7 did not exhibit noticeable decrease in green fluorescence (Fig. 3B).
Quantitative cellular viability on days 1 and 7 are presented in Fig. 3C. The absorbance values at $450 \mathrm{~nm}$ on day 1 were $0.636 \pm 0.074,1.006 \pm 0.250,1.178 \pm 0.275$ and $1.002 \pm 0.257$ for noni at $0,10,100$ and $200 \mathrm{ng} / \mathrm{ml}$, respectively ( $\mathrm{P}>0.05)$. On day 7, the absorbance values were $0.562 \pm 0.093$, $1.331 \pm 0.150,1.811 \pm 0.286$ and $1.652 \pm 0.155$, for noni at 0,10 , 100 and $200 \mathrm{ng} / \mathrm{ml}$, respectively $(\mathrm{P}<0.05)$. Treatment with noni produced significantly higher values in cellular viability compared with the $0 \mathrm{ng} / \mathrm{ml}$ group $(\mathrm{P}<0.05)$, with the highest value at $100 \mathrm{ng} / \mathrm{l}$.

Evaluation of alkaline phosphatase activity and Alizarin Red S staining under osteogenic media. Significantly higher values for alkaline phosphatase activity were observed in the 10 and $100 \mathrm{ng} / \mathrm{ml}$ groups on day 7, with the highest value at $100 \mathrm{ng} / \mathrm{ml}(\mathrm{P}<0.05$; Fig. 4).

Fig. 5A shows the results for Alizarin Red S staining. Calcium deposits were clearly observed in each group on day 7. The absorbance values on day 3 were $0.123 \pm 0.006$, $0.144 \pm 0.006,0.153 \pm 0.007$ and $0.147 \pm 0.006$ for $0,10,100$ and $200 \mathrm{ng} / \mathrm{ml}$, respectively (Fig. 5B). Treatment with noni produced significantly higher values in Alizarin Red $S$ staining, with the highest value from $100 \mathrm{ng} / \mathrm{ml}(\mathrm{P}<0.05)$.

Gene Ontology. Differentially expressed mRNAs in the $10 \mathrm{ng} / \mathrm{ml}$ group vs. the control group are presented in Table SI (fold change $>1.5$ and $\log _{3}$ normalized read counts $>3$ were selected). Comparison of the $10 \mathrm{ng} / \mathrm{ml}$ group vs. the control group revealed that 22 mRNAs were upregulated and 13 were downregulated. Clustering analysis of the differentially expressed mRNAs is presented in Fig. 6A. Bar charts depicting 

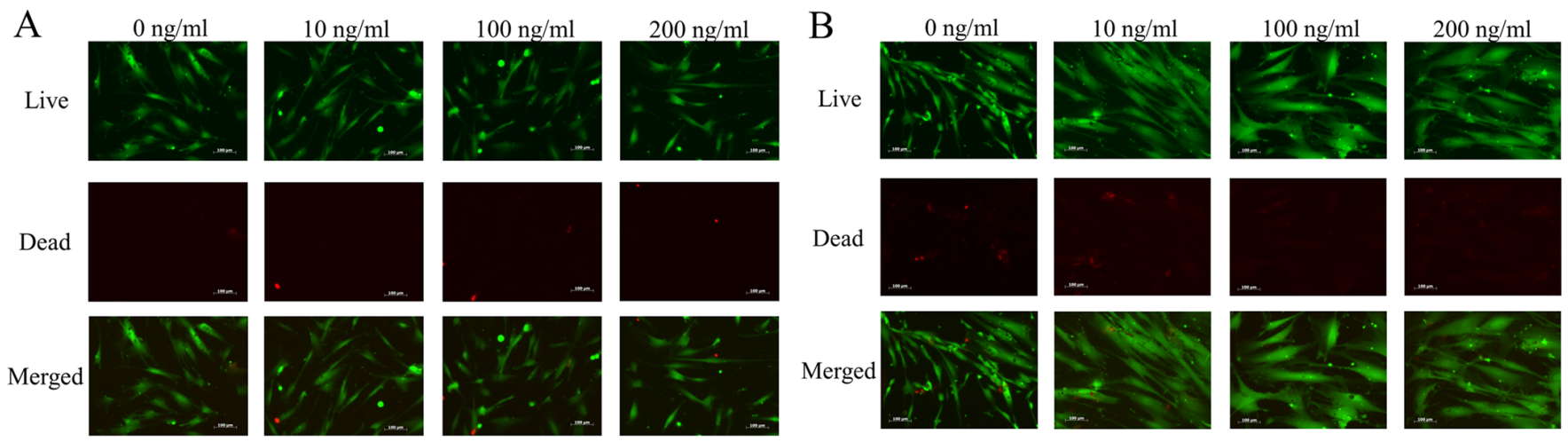

C 2.500
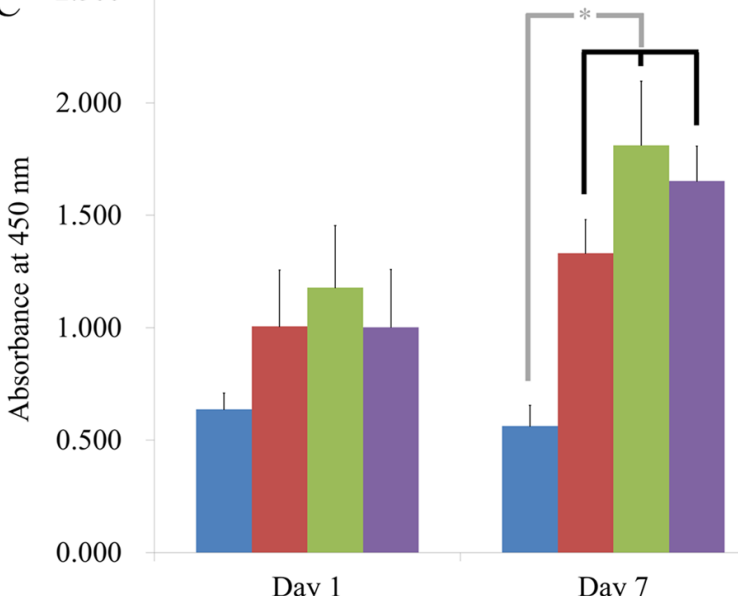

$$
\begin{aligned}
& =0 \mathrm{ng} / \mathrm{ml} \\
& =10 \mathrm{ng} / \mathrm{ml} \\
& =100 \mathrm{ng} / \mathrm{ml} \\
& \square 200 \mathrm{ng} / \mathrm{ml}
\end{aligned}
$$

Figure 3. Evaluation of cell viability. (A) Live, dead and merged images of stem cells on day 1. Most stem cells exhibited green fluorescence following treatment with noni at 0,10,100 and $200 \mathrm{ng} / \mathrm{ml}$ (scale bar, $200 \mu \mathrm{m}$ ). (B) Live, dead and merged images of stem cells on day 7. Most stem cells exhibited green fluorescence, and no significant changes were observed compared with day 1 in each group, respectively (scale bar, $200 \mu \mathrm{m}$ ). (C) Cell viability was assessed via the Cell Counting Kit-8 assay on days 1 and 7. ${ }^{*} \mathrm{P}<0.05$.

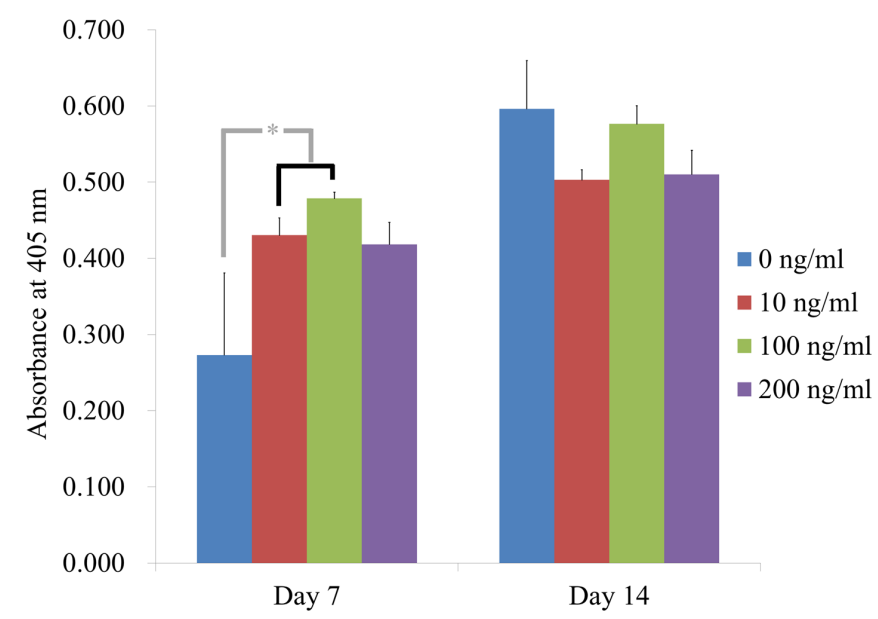

Figure 4. Alkaline phosphatase activity on days 7 and $14 .{ }^{*} \mathrm{P}<0.05$.

the top Gene Ontology terms are presented in Fig. 6B. The most highly associated pathway was 'regulation of cell proliferation'.

Differentially expressed mRNAs in the $100 \mathrm{ng} / \mathrm{ml}$ group vs. the control group are presented in Table SII (fold change $>1.5$ and $\log _{2}$ normalized read counts $>3$ were selected). Comparison of the $100 \mathrm{ng} / \mathrm{ml}$ group vs. the control group revealed that 24 mRNAs were upregulated and 25 were downregulated. Clustering analysis of the differentially expressed mRNAs is presented in Fig. 7A. Bar charts depicting the top gene ontology terms are presented in Fig. 7B. 'Collagen catabolic pathway' was associated with mRNA expression.

Differentially expressed mRNAs in the $200 \mathrm{ng} / \mathrm{ml}$ group vs. the control group are presented in Table SIII (fold change $>1.5$ and $\log _{2}$ normalized read counts $>3$ were selected). Comparison of the $200 \mathrm{ng} / \mathrm{ml}$ group vs. the control group revealed that 23 mRNAs were upregulated and 25 were downregulated. Clustering analysis of the differentially expressed mRNAs is presented in Fig. 8A. Bar charts depicting the top gene ontology terms are presented in Fig. 8B. The most highly associated pathways were 'mRNA splication' and 'translation'. The signaling pathway associated with the target genes was transforming growth factor- $\beta$ (TGF- $\beta$ ) pathway (Fig. 9).

Changes in the expression levels of bone morphogenetic protein $8 \mathrm{~b}$ (BMP8B), parathyroid hormone like hormone (PTHLH), RUNX2 and catenin $\beta-1$ (CTNNB1) are presented in Fig. 10A. The results demonstrated that BMP8B expression was higher in the 10 and $100 \mathrm{ng} / \mathrm{ml}$ noni group compared with the control group (Fig. 10B). Furthermore, RUNX2 expression was higher in the 10 and $200 \mathrm{ng} / \mathrm{ml}$ noni groups compared with the control group. Similarly, CTNNB1 expression was higher in the 10 and $200 \mathrm{ng} / \mathrm{ml}$ noni groups compared with the control group. PTHLH expression was higher in the 100 and $200 \mathrm{ng} / \mathrm{ml}$ noni groups compared with the control group. 

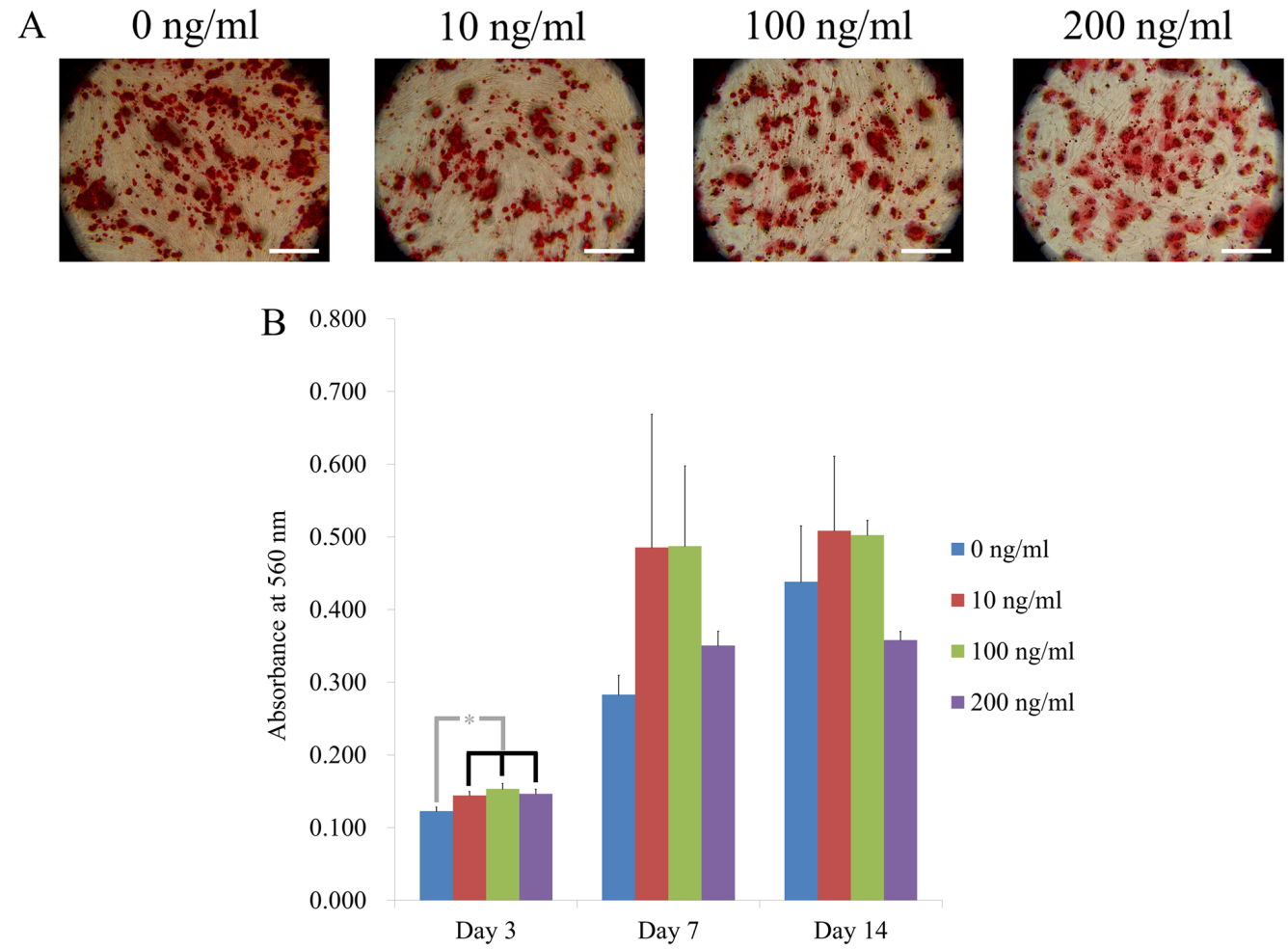

Figure 5. Assessment of calcium deposits. (A) Results of Alizarin Red S staining on day 7. Accumulated calcium nodules were stained with Alizarin Red S in 0, 10, 100 and $200 \mathrm{ng} / \mathrm{ml}$ groups of noni. (B) Quantitative analysis of Alizarin Red S staining on days 3, 7 and 14. "P<0.05.

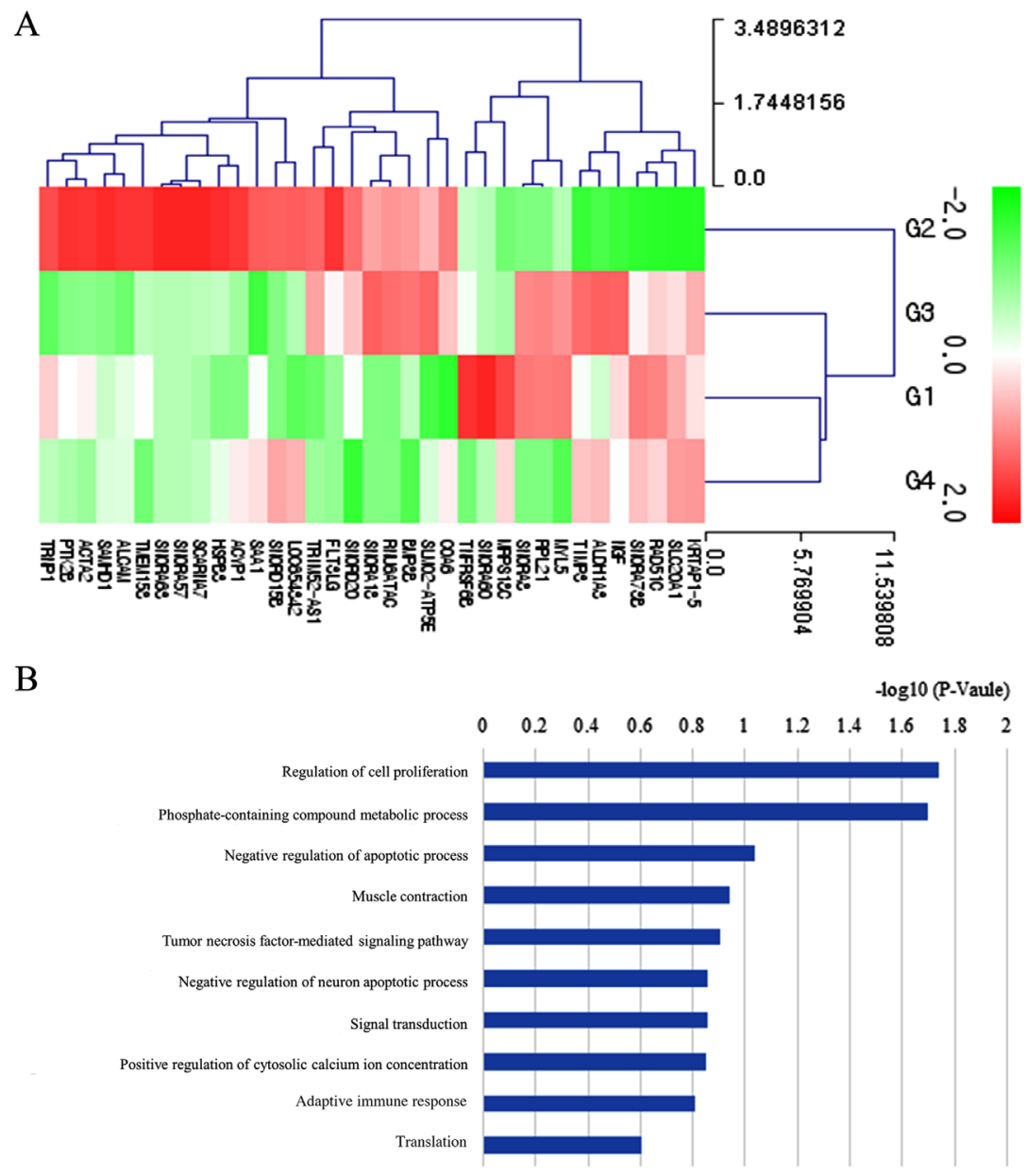

Figure 6. Gene Ontology analysis. (A) Clustering analysis of differentially expressed mRNAs in the $10 \mathrm{ng} / \mathrm{ml}$ group vs. the control group (fold change $>1.5$ and $\log _{2}$ normalized data $>3$ were selected). (B) Gene ontology analysis of the $10 \mathrm{ng} / \mathrm{ml}$ group vs. the control group. Bar charts depict the top gene ontology terms. 


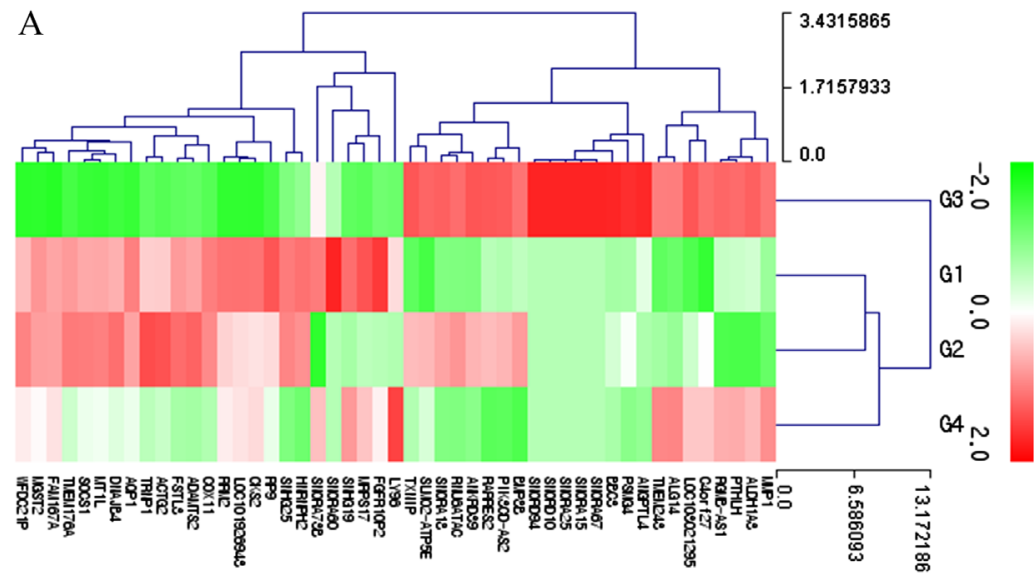

$\mathrm{B}$

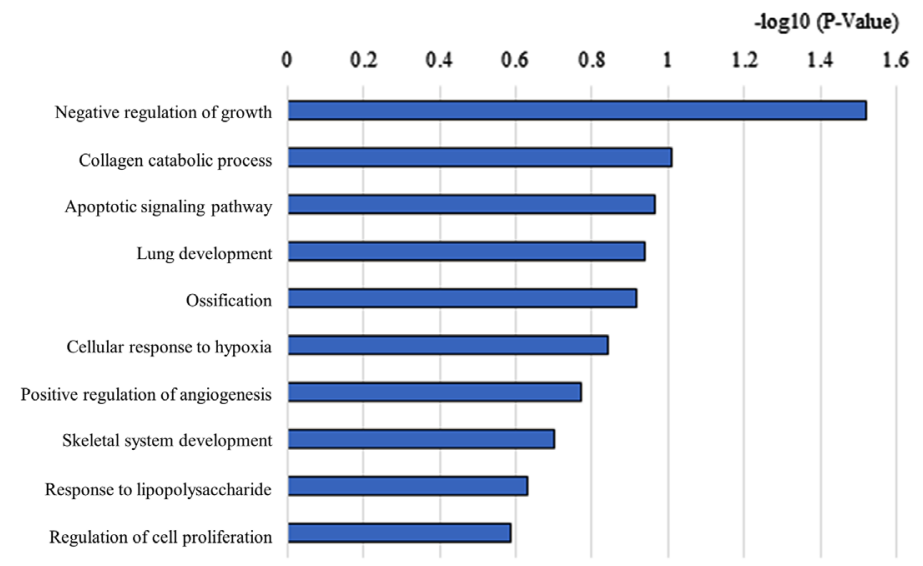

Figure 7. Clustering analysis. (A) Clustering analysis of differentially expressed mRNAs in the $100 \mathrm{ng} / \mathrm{ml}$ group vs. the control group (fold change $>1.5$ and $\log _{2}$ normalized data $>3$ were selected). (B) Gene ontology analysis of the $100 \mathrm{ng} / \mathrm{ml}$ group vs. the control group. Bar charts depict the top gene ontology terms.
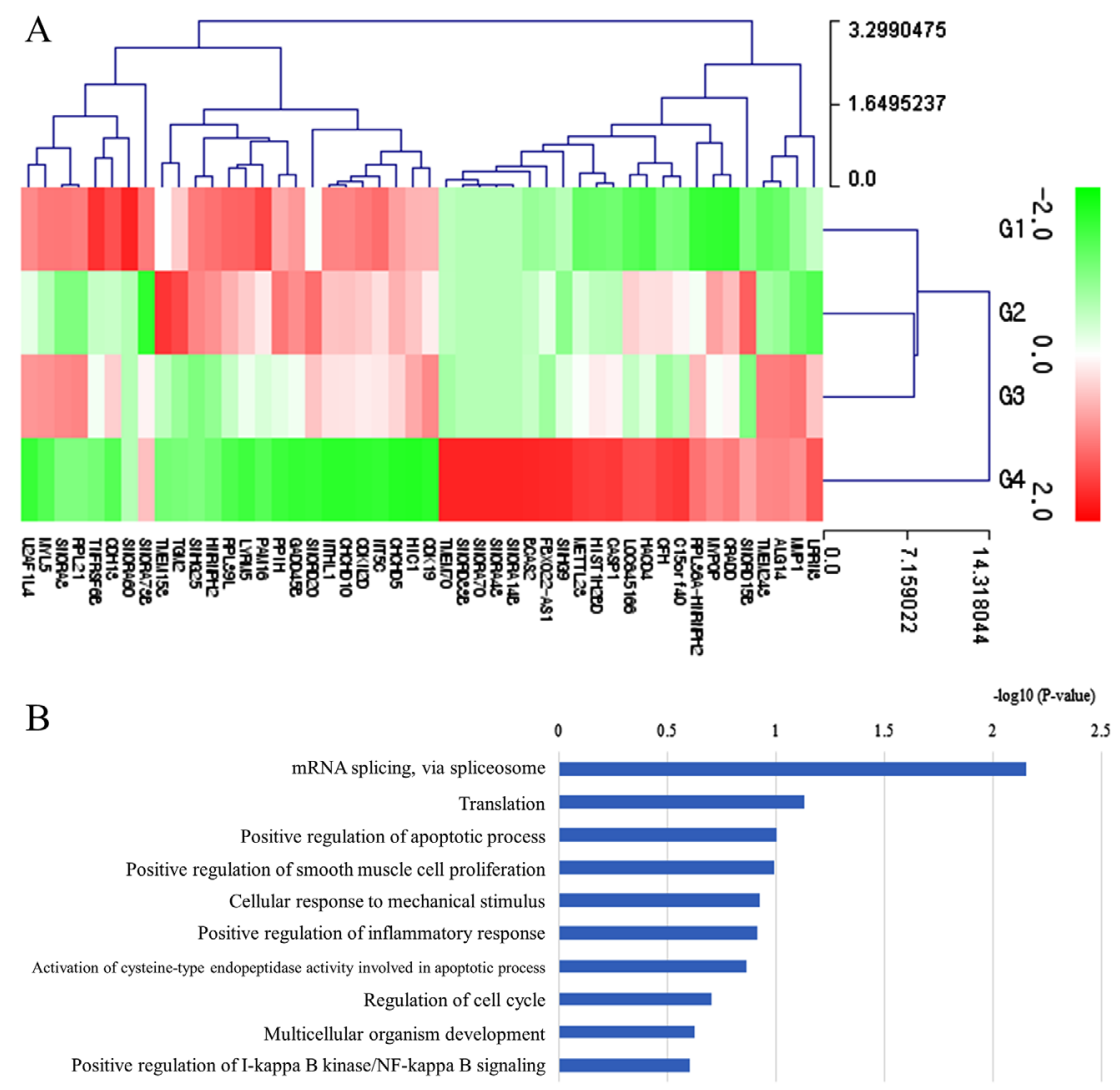

Figure 8. Clustering analysis. (A) Clustering analysis of differentially expressed mRNAs in the $200 \mathrm{ng} / \mathrm{ml}$ group vs. the control group (fold change $>1.5$ and $\log _{2}$ normalized data $>3$ were selected). (B) Gene ontology analysis of the $200 \mathrm{ng} / \mathrm{ml}$ group vs. the control group. Bar charts depict the top gene ontology terms. 


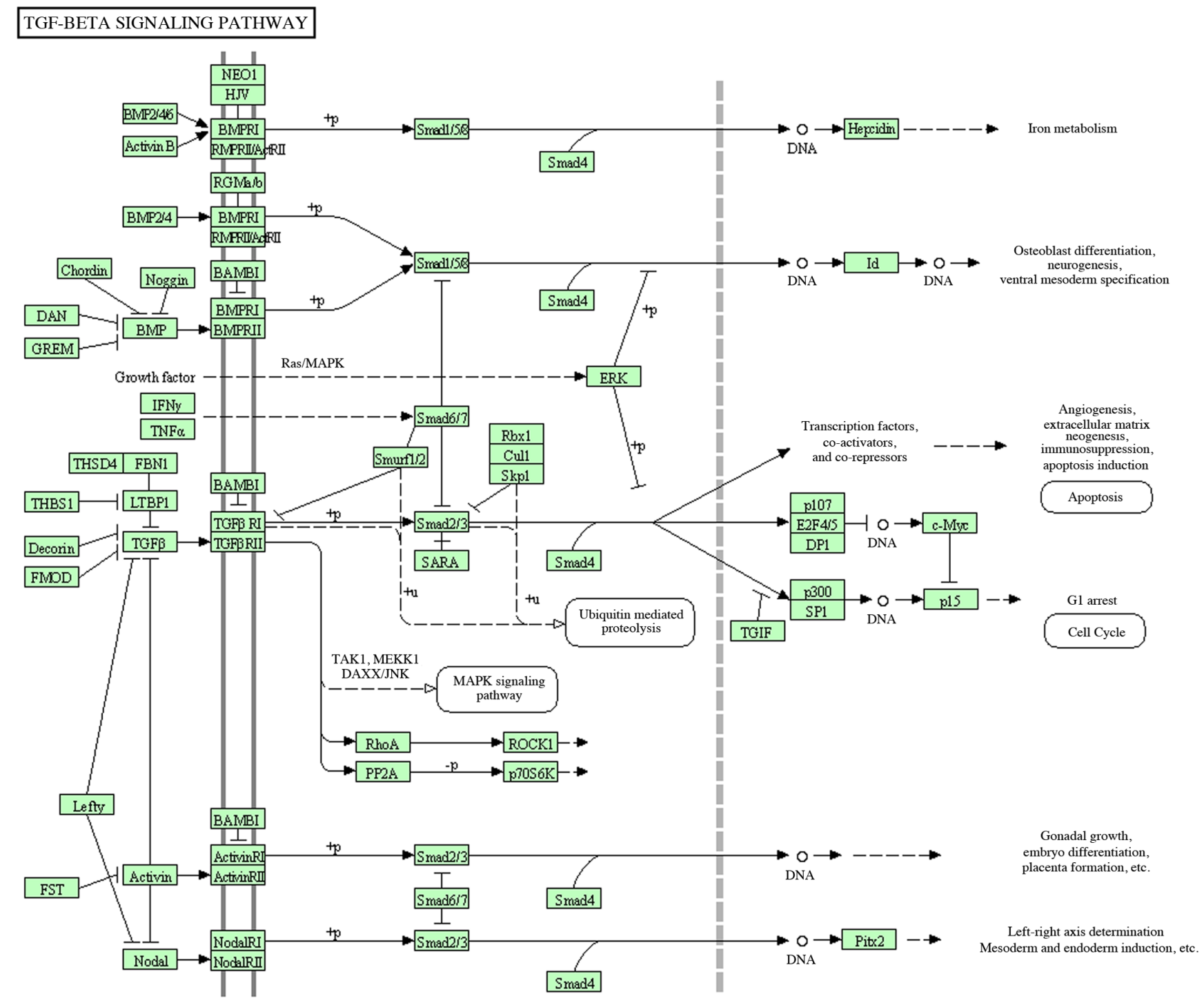

$043508 / 11 / 20$

(c) Kanehisa Laboratories

Figure 9. Pathway analysis. Signaling pathway associated with the target genes was transforming growth factor- $\beta$ pathway.

Evaluation of RUNX2, BSP, OCN and COL1A1 mRNA expression levels via $q P C R$ in osteogenic media. $\mathrm{qPCR}$ analysis demonstrated that RUNX2 mRNA expression levels on day 3 were $1.000 \pm 0.027,1.123 \pm 0.060,0.587 \pm 0.021$ and $0.670 \pm 0.022$ for noni at $0,10,100$ and $200 \mathrm{ng} / \mathrm{ml}$, respectively $(\mathrm{P}<0.05$; Fig. 11A). RUNX2 mRNA expression levels on day 7 were $1.001 \pm 0.050,0.956 \pm 0.085,1.035 \pm 0.073$ and $1.339 \pm 0.092$ for noni at $0,10,100$ and $200 \mathrm{ng} / \mathrm{ml}$, respectively $(\mathrm{P}<0.05)$. Notably, treatment with $200 \mathrm{ng} / \mathrm{ml}$ of noni significantly increased RUNX2 expression at day 7. Furthermore, BSP mRNA expression levels on day 3 were $1.015 \pm 0.204,1.434 \pm 0.370$, $0.812 \pm 0.050$ and $0.365 \pm 0.049$, respectively $(\mathrm{P}<0.05)$ (Fig. 11B). BSP mRNA expression levels on day 7 were $1.001 \pm 0.050$, $0.107 \pm 0.009,2.391 \pm 0.172$ and $0.852 \pm 0.033$ for noni at 0,10 , 100 and $200 \mathrm{ng} / \mathrm{ml}$, respectively $(\mathrm{P}<0.05)$. Notably, treatment with $100 \mathrm{ng} / \mathrm{ml}$ of noni significantly increased BSP expression at day 7. OCN mRNA expression levels on day 3 were $1.001 \pm 0.043,1.773 \pm 0.146,0.759 \pm 0.043$ and $1.924 \pm 0.087$ for noni at $0,10,100$ and $200 \mathrm{ng} / \mathrm{ml}$, respectively $(\mathrm{P}<0.05$; Fig. $11 \mathrm{C})$. OCN mRNA expression levels on day 7 were $1.001 \pm 0.051$,
$1.162 \pm 0.022,1.042 \pm 0.069$ and $1.607 \pm 0.059$ for noni at 0,10 , 100 and $200 \mathrm{ng} / \mathrm{ml}$, respectively $(\mathrm{P}<0.05)$. Notably, treatment with 10 (day 3) and $200 \mathrm{ng} / \mathrm{ml}$ (days 3 and 7) of noni significantly increased OCN expression. COL1A1 mRNA expression levels on day 3 were $1.000 \pm 0.011,1.078 \pm 0.038,0.911 \pm 0.050$ and $0.951 \pm 0.011$ for noni at $0,10,100$ and $200 \mathrm{ng} / \mathrm{ml}$, respectively $(\mathrm{P}<0.05)$ (Fig. 11D). COL1A1 mRNA expression levels on day 7 were $1.001 \pm 0.048,0.735 \pm 0.050,1.275 \pm 0.063$ and $1.259 \pm 0.122$ at $0,10,100$ and $200 \mathrm{ng} / \mathrm{ml}$, respectively $(\mathrm{P}<0.05)$. Notably, treatment with 100 and $200 \mathrm{ng} / \mathrm{ml}$ of noni significantly increased OCN expression at day 7.

\section{Discussion}

The present study investigated the effects of noni extract on maintaining morphology, improving cellular viability and strengthening osteogenic differentiation of dental stem cells.

Several methods have been applied to noni extraction, including cold press, methanol, ethanol, ethyl acetate and hexane extract $(2,24)$, and the extraction method may influence 

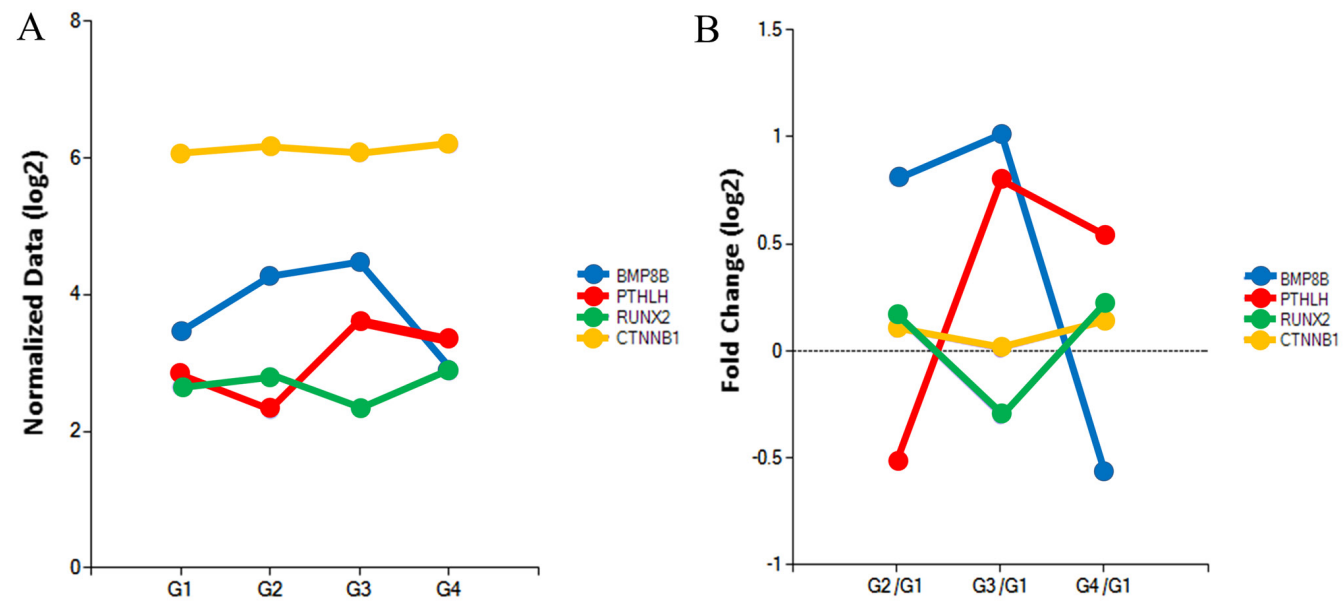

Figure 10. Expression levels of BMP8B, PTHLH, RUNX2 and CTNNB1.(A) $\log _{2}$-normalized read counts regarding the expression levels of BMP8B, PTHLH, RUNX2 and CTNNB1 (for $\beta$-catenin expression). (B) $\log _{2}$ fold change regarding the expression levels of BMP8B, PTHLH, RUNX2 and CTNNB1. BMP8B, bone morphogenetic protein 8b; PTHLH, parathyroid hormone like hormone; CTNNB1, catenin $\beta-1$.
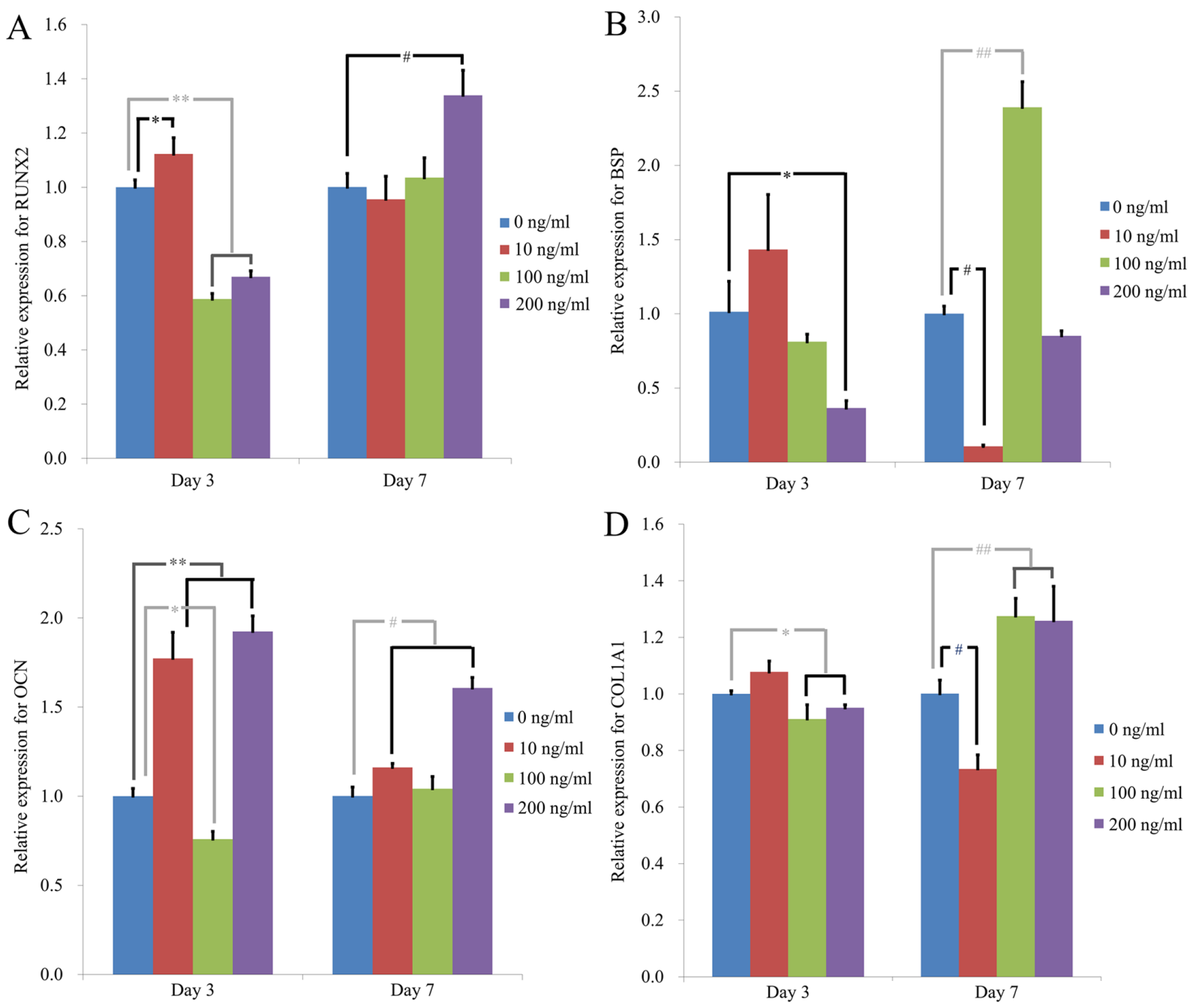

Figure 11. Evaluation of mRNA expression. (A) RUNX2 mRNA expression on days 3 and 7. (B) BSP mRNA expression on days 3 and 7. (C) OCN mRNA expression on days 3 and 7. (D) COL1A1 mRNA expression on days 3 and $7 .{ }^{*} \mathrm{P}<0.05 ;{ }^{* *} \mathrm{P}<0.05 ;{ }^{*} \mathrm{P}<0.05 ;{ }^{\# \#} \mathrm{P}<0.05$.

the results. A previous study reported that ethyl acetate extract has the highest anticancer activity profile (4). In the present study, ripening and freeze-drying processes were applied for the experiments. It has been reported that ripening and aging may influence the antioxidant capacity and the microbiological flora of noni (25).

The dosage may influence the optimal effects, and adverse effects have been reported $(26,27)$. In a previous report, noni at 
a concentration range of $0.015-1.000 \%(\mathrm{w} / \mathrm{v} \%)$ failed to exhibit a cytotoxic effect on human periodontal ligament (28). Similarly, noni was applied at concentrations of $0.0001,0.0100$ and $1.000 \%$ to lymphocytes isolated from lymph nodes (29). Regarding animal models, $50-1,000 \mathrm{mg} / \mathrm{kg}$ of noni extract were applied to a rat model (30). For a mouse model, 3,000-5,000 mg/kg of methanol extract was used (31). For human participants, $2 \mathrm{ml} / \mathrm{kg}$ of noni juice was applied (32). In the present study, the most effective results were obtained in the $100 \mathrm{ng} / \mathrm{ml}$ group. This is consistent with a previous study that assessed the effects of noni using three-dimensional cultures (14). However, no noticeable effects of noni on cellular viability were exhibited, which may be due to the nature of the culture condition and exchange of nutrients, gases and waste materials $(33,34)$.

The mechanism of noni extract can be explained based on a previous report. Noni extract has been reported to enhance the expression of DNA repair genes (35). In addition, it contains various phytochemicals, including damnacanthal, myricetin and ursolic acid (36). Damnacanthal is an anthraquinone known to target p56Ick, PDGFR, erbB2, EGFR and insulin receptor, c-Met receptor tyrosine kinases and has anticancer properties $(37,38)$. Due to its antioxidant effect and its interaction with the immune system and inflammation pathways, several health benefits are associated with noni juice, including periodontal health (39). Phytochemicals of noni fruit have been reported to selectively regulate age-related immunity and antioxidant enzyme activities via the ERK pathways of splenic lymphocytes (36).

The improvement of osteogenic differentiation of noni has also been investigated. BMP8B is a protein-coding gene that encodes a secreted ligand of the TGF- $\beta$ superfamily of proteins (40). The protein encoded by the PTHLH gene is a member of the parathyroid hormone family (41). CTNNB1 is a protein-coding gene, and the protein encoded by this gene is associated with regulating cell proliferation and adhesion between cells $(42,43)$.

Evaluation of several genes, including RUNX2, BSP, OCN and COL1A1 were evaluated via qPCR analysis in the present study. RUNX2 is involved in the regulation of osteogenic differentiation (44), and RUNX2 mutation reduces osteogenic differentiation (45). BSP is involved in the proliferation and osteogenic differentiation of stem cells in vitro (46). Similarly, $\mathrm{OCN}$ is considered a differentiation marker for osteogenic differentiation of stem cells (47). COL1A1 is an early marker of osteogenic differentiation and its expression increases during transformation of osteogenic progenitor cells to osteoblasts (48). In the present study, qPCR analysis demonstrated that the mRNA expression levels of RUNX2, BSP, OCN and COL1A1 increased following treatment with noni. Similarly, a previous study reported that treatment with noni juice promoted osteoblast differentiation by increasing RUNX2 and osteocalcin expression in rat bone marrow stem cells (3). In another study, noni leaf extract enhanced osteogenic differentiation by inducing the PI3K/Akt signaling pathway, which contributed to activation of Wnt/ $\beta$-catenin in C2C12 cells (28). The results of the present study suggest that noni fruit extract enhanced osteogenic differentiation via the TGF- $\beta$ signaling pathway.

Various side effects of noni have been reported in clinical cases. For example, herb-to-drug interactions have reported between phenytoin and the commercial product of noni juice (49). Furthermore, acute liver failure has been associated with the consumption of noni juice (50). Long-term consumption of noni has been reported to change the coagulation profile and intraoperative hemorrhage (51). The limitation of the present study is that the protein expression levels of BMP8B, PTHLH, RUNX2 and CTNNB1 were not verified and protein expression may not correlate with mRNA expression.

In conclusion, the results of the present study demonstrated that treatment with noni extract improved cellular viability and increased osteogenic differentiation. Based on current literature and the results presented here, noni extract may have beneficial effects on dental mesenchymal stem cells by strengthening the cellular viability and osteogenic differentiation. These findings may lead to the discovery of potential natural agents for chronic periodontitis, which may provide clinical benefits for bone regeneration in patients with periodontitis.

\section{Acknowledgements}

Not applicable.

\section{Funding}

The present study was supported by the National Research Foundation of Korea grant funded by the Korea government (MSIT, grant no. 2020R1A2C4001624).

\section{Availability of data and materials}

The datasets generated and/or analyzed during the current study are available in the National Center for Biotechnology Information Sequence Read Archive database repository, ncbi. nlm.nih.gov/bioproject/PRJNA768946/.

\section{Authors' contributions}

YMS, HJL, SKM, YHP, JKO, JYK and JBP conceived the present study. YMS, HJL, SKM, YHP, JKO, JYK and JBP performed the experiments. YMS, HJL, SKM, YHP, JKO, JYK and JBP analyzed the data. YMS, HJL, SKM, YHP, JKO, JYK and JBP drafted the initial manuscript. All authors have read and approved the final manuscript. YHP and JBP confirm the authenticity of all the raw data.

\section{Ethics approval and consent to participate}

The present study was approved by the Institutional Review Board of The Catholic University of Korea after reviewing the protocol (approval nos. KC19SESI0234 and KC20SISE0696; approval date, 07 May 2019) and written informed consent was provided prior to the study start.

\section{Patient consent for publication}

Not applicable.

\section{Competing interests}

The authors declare that they have no competing interests. 


\section{References}

1. Wall MM, Miller S and Siderhurst MS: Volatile changes in Hawaiian noni fruit, Morinda citrifolia L., during ripening and fermentation. J Sci Food Agric 98: 3391-3399, 2018.

2. Palu A, Su C, Zhou BN, West B and Jensen J: Wound healing effects of noni (Morinda citrifolia L.) leaves: A mechanism involving its PDGF/A2A receptor ligand binding and promotion of wound closure. Phytother Res 24: 1437-1441, 2010.

3. Hussain S, Tamizhselvi R, George L and Manickam V: Assessment of the role of Noni (Morinda citrifolia) juice for inducing osteoblas differentiation in isolated rat bone marrow derived mesenchymal stem cells. Int J Stem Cells 9: 221-229, 2016.

4. Sharma K, Pachauri SD, Khandelwal K, Ahmad H, Arya A, Biala P, Agrawal S, Pandey RR, Srivastava A, Srivastav A, et al: Anticancer effects of extracts from the fruit of Morinda Citrifolia (Noni) in breast cancer cell lines. Drug Res (Stuttg) 66: 141-147, 2016.

5. Kumarasamy B, Manipal S, Duraisamy P, Ahmed A, Mohanaganesh S and Jeevika C: Role of aqueous extract of Morinda citrifolia (Indian noni) ripe fruits in inhibiting dental caries-causing Streptococcus mutans and Streptococcus mitis. J Dent (Tehran) 11: 703-710, 2014.

6. Glang J, Falk W and Westendorf J: Effect of Morinda citrifolia L. fruit juice on gingivitis/periodontitis. Mod Res Inflamm 2: 21-27, 2013.

7. Choudhary E, Indushekar KR, Saraf BG, Sheoran N, Sardana D and Shekhar A: Exploring the role of Morinda citrifolia and Triphala juice in root canal irrigation: An ex vivo study. J Conserv Dent 21: 443-449, 2018.

8. Needleman I, Worthington H, Giedrys-Leeper E and Tucker R: Guided tissue regeneration for periodontal infra-bony defects Cochrane Database Syst Rev: Apr 19, 2006 (Epub ahead of print). doi: 10.1002/14651858.CD001724.pub2.

9. Kim YT, Jeong SN and Lee JH: Effectiveness of porcine-derived xenograft with enamel matrix derivative for periodontal regenerative treatment of intrabony defects associated with a fixed dental prosthesis: A 2-year follow-up retrospective study. J Periodontal Implant Sci 51: 179-188, 2021.

10. Langford J, Doughty A, Wang M, Clayton L and Babich M: Effects of Morinda citrifolia on quality of life and auditory function in postmenopausal women. J Altern Complement Med 10: 737-739, 2004.

11. Wang X, Wang Y, Gou W, Lu Q, Peng J and Lu S: Role of mesenchymal stem cells in bone regeneration and fracture repair: A review. Int Orthop 37: 2491-2498, 2013.

12. Lee SI, Ko Y and Park JB: Evaluation of the maintenance of stemness, viability, and differentiation potential of gingiva-derived stem-cell spheroids. Exp Ther Med 13: 1757-1764, 2017.

13. Jin SH, Lee JE, Yun JH, Kim I, Ko Y and Park JB: Isolation and characterization of human mesenchymal stem cells from gingival connective tissue. J Periodontal Res 50: 461-467, 2015.

14. Min SK, Oh J and Park JB: The effects of Morinda citrifolia (Noni) on the cellular viability and osteogenesis of stem cell spheroids. Medicina (Kaunas) 56: 56, 2020.

15. Kang SH, Park JB, Kim I, Lee W and Kim H: Assessment of stem cell viability in the initial healing period in rabbits with a cranial bone defect according to the type and form of scaffold. J Periodontal Implant Sci 49: 258-267, 2019.

16. Kim BB, Tae JY, Ko Y and Park JB: Lovastatin increases the proliferation and osteoblastic differentiation of human gingiva-derived stem cells in three-dimensional cultures. Exp Ther Med 18: 3425-3430, 2019.

17. Lee H, Lee H, Na CB and Park JB: The effects of simvastatin on cellular viability, stemness and osteogenic differentiation using 3 -dimensional cultures of stem cells and osteoblast-like cells. Adv Clin Exp Med 28: 699-706, 2019.

18. Tae JY, Park YH, Ko Y and Park JB: The effects of bone morphogenetic protein- 4 on cellular viability, osteogenic potential, and global gene expression on gingiva-derived stem cell spheroids. Coatings 10: 1055, 2020.

19. Trapnell C, Pachter L and Salzberg SL: TopHat: Discovering splice junctions with RNA-Seq. Bioinformatics 25: 1105-1111, 2009.

20. Roberts A, Trapnell C, Donaghey J, Rinn JL and Pachter L: Improving RNA-Seq expression estimates by correcting for fragment bias. Genome Biol 12: R22, 2011.

21. Kanehisa M, Furumichi M, Tanabe M, Sato Y and Morishima K: KEGG: New perspectives on genomes, pathways, diseases and drugs. Nucleic Acids Res 45: D353-D361, 2017.
22. Lee HJ, Min SK, Park YH and Park JB: Application of bone morphogenetic protein 7 enhanced the osteogenic differentiation and mineralization of bone marrow-derived stem cells cultured on deproteinized bovine bone. Coatings 11: 642, 2021.

23. Livak KJ and Schmittgen TD: Analysis of relative gene expression data using real-time quantitative PCR and the 2(-Delta Delta $\mathrm{C}(\mathrm{T}))$ method. Methods 25: 402-408, 2001.

24. Huang HL, Liu CT, Chou MC, Ko CH and Wang CK: Noni (Morinda citrifolia L.) fruit extracts improve colon microflora and exert anti-inflammatory activities in Caco-2 cells. J Med Food 18: 663-676, 2015.

25. Chan-Blanco Y, Vaillant F, Pérez AM, Belleville M-P, Zúñiga C and Brat P: The ripening and aging of noni fruits (Morinda citrifolia L.): Microbiological flora and antioxidant compounds. J Sci Food Agric 87: 1710-1716, 2007.

26. Singh B and Sharma RA: Indian Morinda species: A review. Phytother Res 34: 924-1007, 2020.

27. Wang M, Wang Q, Yang Q, Yan X,Feng S and Wang Z: Comparison of anthraquinones, iridoid glycosides and triterpenoids in Morinda officinalis and Morinda citrifolia using UPLC/Q-TOF-MS and multivariate statistical analysis. Molecules 25: 25, 2019.

28. Gu H, Boonanantanasarn K, Kang M, Kim I, Woo KM, Ryoo HM and Baek JH: Morinda citrifolia Leaf extract enhances osteogenic differentiation through activation of $\mathrm{Wnt} / \beta$-catenin signaling. J Med Food 21: 57-69, 2018.

29. Pratap UP, Priyanka HP, Ramanathan KR, Raman V, Hima L and Thyagarajan S: Noni (Morinda citrifolia L.) fruit juice delays immunosenescence in the lymphocytes in lymph nodes of old F344 rats. J Integr Med 16: 199-207, 2018.

30. Osman WNW and Mohamed S: Standardized Morinda citrifolia L. and Morinda elliptica L. leaf extracts alleviated fatigue by improving glycogen storage and lipid/carbohydrate metabolism. Phytother Res 32: 2078-2085, 2018.

31. Pandy V, Wai YC, Amira Roslan NF, Sajat A, Abdulla Jallb AH and Vijeepallam K: Methanolic extract of Morinda citrifolia Linn. unripe fruit attenuates methamphetamine-induced conditioned place preferences in mice. Biomed Pharmacother 107: 368-373, 2018.

32. Algenstaedt P, Stumpenhagen A and Westendorf J: The effect of Morinda citrifolia L. fruit juice on the blood sugar level and other serum parameters in patients with diabetes type 2. Evid Based Complement Alternat Med 2018: 3565427, 2018.

33. Park JB, Jeong JH, Lee M, Lee DY and Byun Y: Xenotransplantation of exendin-4 gene transduced pancreatic islets using multi-component (alginate, poly-L-lysine, and polyethylene glycol) microcapsules for the treatment of type 1 diabetes mellitus. J Biomater Sci Polym Ed 24: 2045-2057, 2013.

34. Lee H, Min SK, Park YH and Park JB: The role of insulin-like growth factor- 2 on the cellular viability and differentiation to the osteogenic lineage and mineralization of stem cells cultured on deproteinized bovine bone mineral. Appl Sci (Basel) 10: 5471, 2020.

35. Gupta RK, Bajpai D and Singh N: Influence of Morinda citrifolia (Noni) on expression of DNA repair genes in cervical cancer cells. Asian Pac J Cancer Prev 16: 3457-3461, 2015.

36. Pratap UP, Anand K, Yasmine F, Hima L, Priyanka HP and Thyagarajan S: Phytochemicals in Morinda citrifolia fruit selectively modulate age-associated immunity and antioxidant enzyme activities through ERK pathway in splenic lymphocytes of male F344 rats. J Recept Signal Transduct Res 36: 139-151, 2015.

37. García-Vilas JA, Quesada AR and Medina MA: Damnacanthal, a noni anthraquinone, inhibits c-Met and is a potent antitumor compound against Hep G2 human hepatocellular carcinoma cells. Sci Rep 5: 8021, 2015.

38. Garcia-Vilas JA, Medina MA, Melo FR, Pejler G and Garcia-Faroldi G: Damnacanthal inhibits IgE receptor-mediated activation of mast cells. Mol Immunol 65: 86-93, 2015.

39. West BJ, Deng S, Isami F, Uwaya A and Jensen CJ: The potential health benefits of noni juice: A review of human intervention studies. Foods 7: 7, 2018

40. Whittle AJ, Carobbio S, Martins L, Slawik M, Hondares E, Vázquez MJ, Morgan D, Csikasz RI, Gallego R, RodriguezCuenca $\mathrm{S}$, et al: BMP8B increases brown adipose tissue thermogenesis through both central and peripheral actions. Cell 149: 871-885, 2012

41. Pieles O, Reck A and Morsczeck C: High endogenous expression of parathyroid hormone-related protein (PTHrP) supports osteogenic differentiation in human dental follicle cells. Histochem Cell Biol 154: 397-403, 2020 
42. Stuss M, Migdalska-Sek M, Brzezianska-Lasota E, MichalskaKasiczak M, Bazela P and Sewerynek E: Assessment of Wnt pathway selected gene expression levels in peripheral blood mononuclear cells (PBMCs) of postmenopausal patients with low bone mass. Bosn J Basic Med Sci 21: 461-470, 2021.

43. Kim BB, Kim M, Park YH, Ko Y and Park JB: Short-term application of dexamethasone on stem cells derived from human gingiva reduces the expression of RUNX2 and $\beta$-catenin. J Int Med Res 45: 993-1006, 2017.

44. Komori T: Regulation of osteoblast differentiation by Runx 2 . Adv Exp Med Biol 658: 43-49, 2010.

45. Liu Y, Wang Y, Sun X, Zhang X, Wang X, Zhang C and Zheng S RUNX2 mutation reduces osteogenic differentiation of dental follicle cells in cleidocranial dysplasia. Mutagenesis 33: 203-214, 2018.

46. Xia B, Wang J, Guo L and Jiang Z: Effect of bone sialoprotein on proliferation and osteodifferentiation of human bone marrow-derived mesenchymal stem cells in vitro. Biologicals 39: 217-223, 2011.

47. Lee H, Song Y, Park YH, Uddin MS and Park JB: Evaluation of the effects of Cuminum cyminum on cellular viability, osteogenic differentiation and mineralization of human bone marrow-derived stem cells. Medicina (Kaunas) 57: 57, 2021.
48. Kannan S, Ghosh J and Dhara SK: Osteogenic differentiation potential of porcine bone marrow mesenchymal stem cell subpopulations selected in different basal media. Biol Open 9: 9, 2020

49. Kang YC, Chen MH and Lai SL: Potentially unsafe herb-drug interactions between a commercial product of noni juice and phenytoin - a case report. Acta Neurol Taiwan 24: 43-46, 2015.

50. Garrido-Gallego F, Muñoz-Gómez R, Muñoz-Codoceo C, Delgado-Álvarez P, Fernández-Vázquez I and Castellano G: Acute liver failure in a patient consuming Herbalife products and Noni juice. Rev Esp Enferm Dig 107: 247-248, 2015.

51. Panditrao MM, Panditrao MM, Edghill F and Lockhart HF: Can Chronic consumption of noni (Morinda citrifolia) juice lead to changes in the coagulation profile, deranged liver function and excessive intraoperative haemorrhage? West Indian Med J 63: 814-815, 2014.

This work is licensed under a Creative Commons Attribution-NonCommercial-NoDerivatives 4.0 International (CC BY-NC-ND 4.0) License. 